\title{
Neurodegenerative changes initiated by presynaptic dysfunction
}

\author{
Toru Yasuda ${ }^{1,2}$, Yasuto Nakata ${ }^{1}$, Chi-Jing Choong ${ }^{1}$ and Hideki Mochizuki ${ }^{*}$
}

\begin{abstract}
a-Synucleinopathies are a subgroup of neurodegenerative diseases including dementia with Lewy bodies (DLB) and Parkinson's disease (PD). Pathologically, these disorders can be characterized by the presence of intraneuronal aggregates composed mainly of a-synuclein (aSyn), which are called Lewy bodies and Lewy neurites. Recent report showed that more than $90 \%$ of aSyn aggregates are present in the form of very small deposits in presynaptic terminals of the affected neurons in DLB. However, the mechanisms responsible for presynaptic accumulation of abnormal aSyn remain unclear. In this article, we review recent findings on the involvement of presynaptic dysfunction in the initiation of neuronal dysfunctional changes. This review highlights that the presynaptic failure can be a potential trigger of the dying-back neuronal death in neurodegenerative diseases.
\end{abstract}

\section{Introduction}

Neurodegenerative diseases are age-associated and progressive disorders, which detrimentally affect patients' quality of life. Medical remedies that can fully cure the diseases are currently unavailable and invention of novel therapeutic applications is urgently required. Accordingly, it is important to identify the initial trigger(s) of the pathophysiological alterations in these diseases.

$\alpha$-Synucleinopathies are a subgroup of neurodegenerative diseases including dementia with Lewy bodies (DLB), Parkinson's disease (PD), and multiple system atrophy (MSA). Pathological hallmark of these disorders is the formation of intracellular aggregates composed mainly of $\alpha$-synuclein ( $\alpha$ Syn), which are called Lewy bodies and Lewy neurites [1-3]. Pathological examination of DLB patients has identified the presence of abnormal $\alpha$-synuclein ( $\alpha$ Syn) aggregates in the presynaptic terminals [4-6]. However, the mechanisms responsible for presynaptic accumulation of abnormal $\alpha$ Syn remain elusive.

\section{Role of aSyn in SNARE formation}

$\alpha$ Syn is abundantly localized in the presynaptic nerve terminals $[7,8]$. The physiological functions of $\alpha$ Syn have yet to be defined, while several lines of evidence implicated this protein in the modulation of neurotransmitter

\footnotetext{
* Correspondence: hmochizuki@neurol.med.osaka-u.ac.jp

'Department of Neurology, Osaka University Graduate School of Medicine,

Suita, Osaka, Japan

Full list of author information is available at the end of the article
}

release through the regulation of soluble $N$-ethylmaleimide-sensitive factor attachment protein receptor (SNARE) complex formation [9-11] and size of synaptic vesicle pool [12-15]. Vesicle-associated membrane protein-2 (VAMP-2) present in the synaptic vesicles, and syntaxin and synaptosomal-associated protein of $25 \mathrm{KDa}$ (SNAP-25) in the presynaptic plasma membrane form the core SNARE complex, which regulate docking and fusion of synaptic vesicles to the presynaptic membrane [16]. A recent study showed the physical interaction of $\alpha$ Syn with VAMP-2 promotes SNARE assembly [10]. Cysteine-string protein- $\alpha(\mathrm{CSP} \alpha)$ also participates in SNARE assembly and mutant mice lacking CSP $\alpha$ displayed impaired SNARE formation and premature death, but both of these phenotypes are counteracted by transgenic expression of $\alpha$ Syn $[9,17]$. On the other hand, overexpression of $\alpha$ Syn with no overt toxicity inhibits neurotransmitter release, due to a defective reclustering of synaptic vesicles after endocytosis [15]. Additionally, overexpressed $\alpha$ Syn indirectly inhibits SNARE-mediated exocytosis by sequestering arachidonic acid, which upregulates syntaxin and enhances its engagement with SNARE complex [11]. Importantly, abnormal redistribution of SNARE proteins has been observed in human PD patients and mice overexpressing a truncated form of human $\alpha$ Syn, which showed decreased release of dopamine (DA) in the striatum [18]. Therefore, presynaptic SNARE dysfunction is considered an initial pathogenic event in $\alpha$-synucleinopathies. 


\section{Accumulation of a-synuclein triggered by presynaptic dysfunction}

In our recent study, we investigated the effects of SNARE dysfunction on endogenous $\alpha$ Syn using Snap $25^{\text {S187A/S187A }}$ mutant mice [19]. These mice have homozygous knockin gene encoding unphosphorylatable S187A-substituted SNAP-25. Snap $25^{\text {S187A/S187A }}$ mutant mice present a concomitant reduction of neurotransmitter release, including serotonin and DA, from the amygdala, and develop convulsive seizures and anxiety-related behavior in general activity and light-and-dark preference tests [20]. We found that the mutant mice displayed a significant agedependent change in the distribution of $\alpha$ Syn and its Ser ${ }^{129}$-phosphorylated form in abnormally hypertrophied glutamatergic nerve terminals in the striatum. Electron microscopic analysis revealed the atypically condensed synaptic vesicles with concomitant mislocalization of $\alpha$ Syn protein to the periactive zone in the glutamatergic nerve terminals (Figure 1). However, the Snap $25^{\text {S187A/S187A }}$ mutant mice harbored no abnormalities in the nigrostriatal dopaminergic neurons [19]. Our results suggest that SNARE dysfunction is the initial trigger of mislocalization and accumulation of $\alpha$ Syn, and probably underlies the pathomechanism of $\alpha$-synucleinopathies.

\section{Effect of SNAP-25 dysfunction}

Previous studies using neural preparations showed that the neurotransmitter release is regulated by protein kinase C, which phosphorylates $\operatorname{Ser}^{187}$ residue in SNAP-25, augmenting exocytosis of synaptic vesicles [21,22]. Patchclamp analysis showed chromaffin cells that overexpressed the S187A mutant form of SNAP-25 had impaired rate of presynaptic vesicle pool refilling [23]. Recently, we reported that Snap $25^{\text {S187A/S187A }}$ mice showed reduced DA and serotonin release in amygdala [20]. In human DLB brains, more than $90 \%$ of $\alpha$ Syn aggregates are located in the presynaptic terminals in the form of small deposits [4-6]. This is consistent with our findings of abnormal accumulation of $\alpha$ Syn in presynapses [19], suggesting that this process is the initial pathological event in DLB, eventually leading to the death and degeneration of neuronal cells [24]. Another finding that lends support to the role of $\alpha$ Syn aggregates in the presynaptic terminals in DLB is the lack of histopathological changes in the dopaminergic terminals in our study [19].

\section{Role of aSyn in nerve terminals}

In experiments on glutamate release conducted in hippocampal slices prepared from $\alpha$ Syn knockout mice [25], paired-pulse facilitation was significantly weaker, and high-frequency-induced long-term potentiation and frequency facilitation were not observed. These findings suggest that $\alpha$ Syn contributes to mobilization of glutamate-containing vesicles from the reserve pool [25]. $\alpha$ Syn may act as a positive regulator of neurotransmitter release at presynaptic terminals. Therefore, presynaptic accumulation of $\alpha$ Syn observed in our Snap $25^{\text {S187A/S187A }}$ mice might reflect a compensatory response to a possible SNARE dysfunction-related chronic shortage of neurotransmitter release in the VGLUT1-positive nerve terminals [19].

\section{Relation between glutamatergic and dopaminergic nerve} terminals in the striatum

In the striatum, the medium spiny neurons, which constitute more than $90 \%$ of all striatal neurons, receive
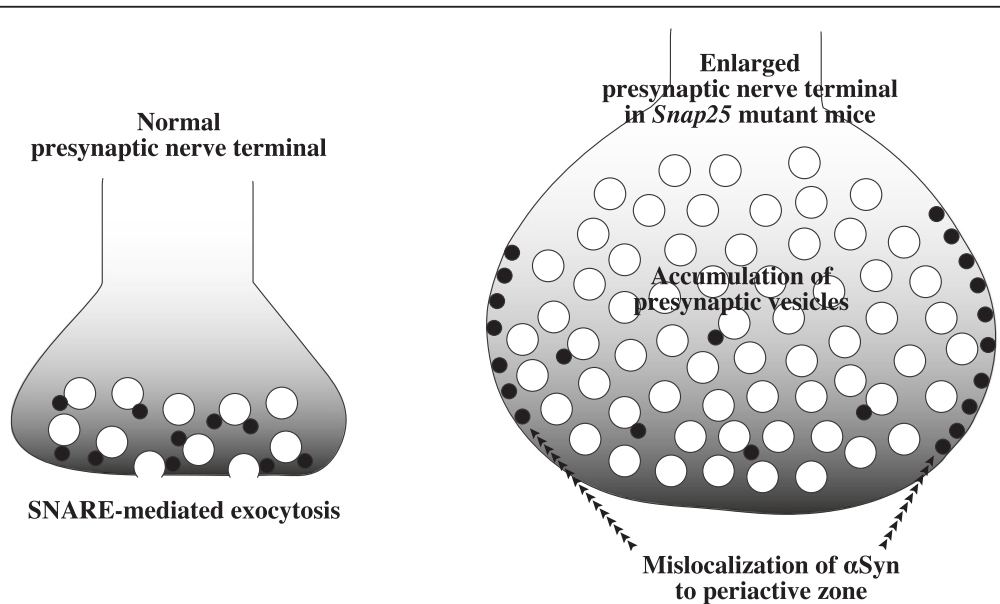

Figure 1 A hypothetical diagram showing enlarged presynaptic nerve terminals in SNAP-25 mutant mice. Normal presynaptic nerve terminals with uniform distribution of vesicles were observed in wild type mice while abnormally enlarged presynaptic nerve terminals with condensed synaptic vesicles and predominant localization of aSyn proteins in the periactive zones were found in SNAP-25 mutant mice, suggesting that SNARE dysfunction leads to presynaptic accumulation of endogenous aSyn and perturbations to the finely-tuned balance between exocytosis and endocytosis. 
input from glutamatergic axons that contact the spine head and dopaminergic axons that synapse with the dendritic spine neck. DA released from dopaminergic axons regulates the release of glutamate via $D_{2}$-like receptors on the corticostriatal nerve terminals [26,27]. We found no significant changes in the striatal tissue levels of DA and its metabolites in Snap $25^{\text {S187A/S187A }}$ mice. These findings confirmed the results reported in our previous study using the same mouse model, in which the microdialysis analysis revealed marked reduction of DA release from the amygdala [20]. In another in vitro study using PC12 cells, phosphorylation of SNAP-25 at S187 potentiated calcium-dependent DA release and recruitment of synaptic vesicles containing DA [28-30]. These observations suggest decreased striatal DA release in Snap $25^{\text {S187A/S187A }}$ mice, resulting in increased demand for neurotransmitter release at glutamatergic nerve terminals. Thus, presynaptic accumulation of $\alpha$ Syn might reflect a possible compensatory response to low DA inhibitory control over cortical glutamatergic drive.

\section{Correlation of VAMP-2 with aSyn}

Increased expression of VAMP-2 protein accompanied increased $\alpha$ Syn expression in the striatum of Snap $25^{\text {S187A/S187A }}$ mice [19]. Binding of the carboxy terminus of $\alpha$ Syn to the amino terminus of VAMP-2 primes subsequent SNARE complex assembly [31]. Therefore, the increased VAMP-2 level might also reflect a compensatory response to the impaired synaptic vesicle release by enhancing SNARE complex formation in concert with increased $\alpha$ Syn.

\section{Pathological changes in glutamatergic nerve terminals}

Presynaptic neurotransmitter release is mediated by the synaptic vesicle cycle, consisting of exocytosis followed by endocytosis and recycling. Exocytosis incorporates synaptic vesicles into the presynaptic terminal membranes and increases the surface area, while endocytosis retrieves excess plasma membrane components followed by recycling to form other synaptic vesicles. Under normal conditions, the dynamics of balance between exocytosis and endocytosis are well preserved to maintain the correct surface area of the presynaptic terminal $[32,33]$. However, a mutant leucine-rich repeat kinase 2 (LRRK2) bacterial artificial chromosome (BAC) transgenic mouse model showed enlarged axonal endings in the striatal dopaminergic neurons, suggesting imbalance between exocytotic membrane addition and endocytic retrieval [34]. Excessive accumulation of presynaptic vesicles and enlargement of the VGLUT1-positive nerve terminals was also observed in Snap25 $5^{\text {S187A/S187A }}$ mice [19]. Taking into consideration the synaptic vesicle cycle, our findings suggest that the balance of the cycle is likely biased toward decreased endocytosis.
The enlarged VGLUT1-positive nerve terminals of Snap $25^{\text {S187A } \$ \text { S187A }}$ mice showed concomitant accumulation of $\alpha$ Syn and p- $\alpha$ Syn [19]. Kramer and SchulzSchaeffer [5] have previously reported that $90 \%$ or even more of $\alpha$ Syn aggregates in DLB cases were located at the presynapses in the form of very small deposits. In parallel, dendritic spines were retracted, whereas the presynapses were relatively preserved, suggesting that neurotransmitter deprivation may explain the cognitive impairment in DLB $[5,6]$. While the presynaptic aggregates did not contain much $\mathrm{p}-\alpha \mathrm{Syn}$ in their examination [5,6], widespread varicosities and dot-like structures containing $\mathrm{p}-\alpha$ Syn are commonly observed in $\alpha$ Syntransgenic mouse model and human DLB brains $[35,36]$. This may represent axonal transport defects and presynaptic dysfunctions $[35,36]$. Recent study showed that mutant $\alpha$ Syn (A53T) diminished levels of various motor proteins in neurons [37], supporting this scenario. Alternatively, excessive amount of misfolded $\alpha$ Syn and $p$ - $\alpha$ Syn may aggregate at synapses, physically preventing the targeting of other presynaptic proteins [5]. In experiments using Caenorhabditis elegans overexpressing human $\alpha$ Syn, four genes related to the endocytosis process were identified as genetic modifiers for $\alpha$ Syn toxicity [38]. They included two subunits of the adaptor protein (AP) complex 2, which interacts with clathrin and promotes presynaptic clathrin-mediated vesicle recycling [39]. Furthermore, proteomics analysis revealed that $\mathrm{p}-\alpha \mathrm{Syn}$ also preferentially interacted with the proteins involved in endocytosis, including clathrin heavy chain and subunit of AP-2 and AP-1 complexes, over the non-phosphorylated $\alpha$ Syn [40]. Clathrin-mediated recycling of exocytosed synaptic vesicles occurs in the periactive zone, a region adjacent to the active zone where synaptic vesicle is endocytosed [33]. Similarly, in Snap $25^{\text {S187A/S187A }}$ mice, immunoelectron microscopy showed preferential localization of $\alpha$ Syn at the periactive zone of excitatory presynaptic nerve terminals. This might reflect the interaction of $\alpha$ Syn and $\mathrm{p}-\alpha$ Syn with the proteins involved in clathrin-mediated endocytosis. Taking these findings together, presynaptic accumulation of $\alpha$ Syn and $p-\alpha$ Syn could disturb the endocytosis process and consequently contribute to the development of VGLUT1-positive terminal enlargement [19].

\section{Presynaptic accumulation of aSyn}

Presynaptic accumulation of $\alpha$ Syn is considered an early event in the pathogenesis of $\alpha$-synucleinopathies [4-6]. Mice overexpressing human $\alpha$ Syn showed presynaptic accumulation of $\alpha$ Syn and low DA release in the striatum. Stoica et al. [41] reported a "dying back" type of neuronal alteration, progressing from the dendrites to the axon and then to the perikaryon and nucleus in a spontaneously inherited autosomal recessive rat model for PD that overexpressed $\alpha$ Syn in mesencephalic area. 
Transmission electron microscopy (TEM) examination revealed that the retrograde pathological process in substantia nigra and striatum starts at the synaptic level by marked presynaptic accumulation of $\alpha$ Syn followed by post-synaptic degeneration of axonal terminals, dendrites and spine alterative changes and perikaryal aggregation of mitochondria with relative preservation of neuronal nuclei. These findings were associated with abnormal distribution of SNARE proteins, which colocalized with $\alpha$ Syn aggregates. Similarly, accumulation of SNARE proteins and $\alpha$ Syn were reported in the striatum of PD patients [18]. These observations suggest that SNARE dysfunction likely occurs at an early stage of pathogenesis in nigrostriatal dysfunction observed in PD. Considering the findings observed in the VGLUT1-positive nerve terminals, we expected that SNARE dysfunction might have induced presynaptic accumulation of $\alpha$ Syn, which consequently result in the development of neurodegenerative changes in the nigrostriatal system. However, contrary to our expectation, Snap $25^{\text {S187A/S187A }}$ mice showed no significant neurodegenerative changes in nigrostriatal dopaminergic neurons, suggesting that SNARE dysfunction alone was insufficient to cause nigrostriatal degeneration as observed in PD, and appeared to be a downstream event associated with abnormal accumulation of $\alpha$ Syn.

\section{Conclusion}

In conclusion, SNARE dysfunction leads to accumulation of endogenous $\alpha$ Syn in the corticostriatal nerve terminals. Presynaptic accumulation of $\alpha \mathrm{Syn}$ is considered to be an early key event in the pathogenesis of $\alpha$-synucleinopathies. Although the "prion-like" propagation hypothesis of $\alpha$ Syn, including tau and TAR DNA-binding protein $43 \mathrm{kDa}$, is currently receiving considerable attention worldwide, our findings provide an insight to understanding of the possible mechanisms that lead to presynaptic accumulation of endogenous $\alpha$ Syn. Moreover, given that SNAP-25 is reduced in the striatum of MSA brains [42], we speculate that a discontinuous pattern of $\alpha$ Syn pathologies usually found in MSA, i.e. glial cytoplasmic inclusions (GCIs) in the putaminal oligodendrocytes, and neuronal cytoplasmic inclusions (NCIs) and neuronal nuclear inclusions (NNIs) in the cortex [43,44], might be potentially linked through the presynaptic accumulation of $\alpha$ Syn in the corticostriatal neurons. Further investigations on the Snap25 mutant mice with genetic ablation of $\alpha$ Syn would contribute to understanding the essential role of redistributed $\alpha$ Syn.

\section{Competing interest}

The authors have no conflict of interest.

\section{Authors' contribution}

TY, YN, and CJC wrote the paper. HM supervised the work. All authors read and approved the final manuscript.

\section{Acknowledgment}

This work was supported by Grants from the Japan Science and Technology Agency (JST), Core Research for Evolutional Science and Technology (CREST) (to H.M.); Grants-in-Aid from the Research Committee of CNS Degenerative Diseases, the Ministry of Health, Labour and Welfare of Japan (to H.M.); a Research Grant for Longevity Sciences from the Ministry of Health, Labour and Welfare of Japan (to H.M.); grants (\#S0801035) from the Ministry of Education, Culture, Sports, Science, and Technology (MEXT) of Japan (to H. M.); and Grant-in-Aid for Scientific Research on Innovative Areas (Comprehensive Brain Science Network) from the Ministry of Education, Science, Sports and Culture of Japan (to H.M.).

\section{Author details}

'Department of Neurology, Osaka University Graduate School of Medicine, Suita, Osaka, Japan. ${ }^{2}$ Present address: Department of Genetics, National Center for Child Health and Development, Setagaya-ku, Tokyo, Japan.

Received: 13 June 2013 Accepted: 5 August 2013

Published: 7 August 2013

\section{References}

1. Spillantini MG, Goedert M: The alpha-synucleinopathies: Parkinson's disease, dementia with Lewy bodies, and multiple system atrophy. Ann N Y Acad Sci 2000, 920:16-27.

2. Galvin JE, Lee VM, Trojanowski JQ: Synucleinopathies: clinical and pathological implications. Arch Neurol 2001, 58:186-190.

3. Yasuda T, Nakata Y, Mochizuki H: Alpha-synuclein and neuronal cell death. Mol Neurobiol 2013, 47(2):466-483.

4. Neumann M, Kahle PJ, Giasson Bl, Ozmen L, Borroni E, Spooren W, Muller V, Odoy S, Fujiwara H, Hasegawa M, Iwatsubo T, Trojanowski JQ, Kretzschmar HA, Haass C: Misfolded proteinase K-resistant hyperphosphorylated alpha-synuclein in aged transgenic mice with locomotor deterioration and in human alpha-synucleinopathies. J Clin Invest 2002, 110:1429-1439.

5. Kramer ML, Schulz-Schaeffer WJ: Presynaptic alpha-synuclein aggregates, not Lewy bodies, cause neurodegeneration in dementia with Lewy bodies. J Neurosci 2007, 27:1405-1410.

6. Schulz-Schaeffer WJ: The synaptic pathology of alpha-synuclein aggregation in dementia with Lewy bodies, Parkinson's disease and Parkinson's disease dementia. Acta Neuropathol 2010, 120:131-143.

7. Maroteaux L, Campanelli JT, Scheller RH: Synuclein: a neuron-specific protein localized to the nucleus and presynaptic nerve terminal. J Neurosci 1988, 8:2804-2815.

8. Iwai A, Masliah E, Yoshimoto M, Ge N, Flanagan L, de Silva HA, Kittel A, Saitoh T: The precursor protein of non-A beta component of Alzheimer's disease amyloid is a presynaptic protein of the central nervous system. Neuron 1995, 14:467-475.

9. Chandra S, Gallardo G, Fernandez-Chacon R, Schluter OM, Südhof TC: Alpha-synuclein cooperates with CSPalpha in preventing neurodegeneration. Cell 2005, 123:383-396

10. Burre J, Sharma M, Tsetsenis T, Buchman V, Etherton MR, Südhof TC: Alpha-synuclein promotes SNARE-complex assembly in vivo and in vitro. Science 2010, 329:1663-1667.

11. Darios F, Ruiperez V, Lopez I, Villanueva J, Gutierrez LM, Davletov B: Alpha-synuclein sequesters arachidonic acid to modulate SNAREmediated exocytosis. EMBO Rep 2010, 11:528-533.

12. Murphy DD, Rueter SM, Trojanowski JQ, Lee VM: Synucleins are developmentally expressed, and alpha-synuclein regulates the size of the presynaptic vesicular pool in primary hippocampal neurons. J Neurosci 2000, 20:3214-3220.

13. Cabin DE, Shimazu K, Murphy D, Cole NB, Gottschalk W, Mcllwain KL, Orrison B, Chen A, Ellis CE, Paylor R, Lu B, Nussbaum RL: Synaptic vesicle depletion correlates with attenuated synaptic responses to prolonged repetitive stimulation in mice lacking alpha-synuclein. J Neurosci 2002, 22:8797-8807.

14. Larsen KE, Schmitz Y, Troyer MD, Mosharov E, Dietrich P, Quazi AZ, Savalle M, Nemani V, Chaudhry FA, Edwards RH, Stefanis L, Sulzer D: Alpha-synuclein overexpression in PC12 and chromaffin cells impairs catecholamine release by interfering with a late step in exocytosis. J Neurosci 2006, 26:11915-11922.

15. Nemani VM, Lu W, Berge V, Nakamura K, Onoa B, Lee MK, Chaudhry FA, Nicoll RA, Edwards RH: Increased expression of alpha-synuclein reduces 
neurotransmitter release by inhibiting synaptic vesicle reclustering after endocytosis. Neuron 2010, 65:66-79.

16. Südhof TC: The synaptic vesicle cycle. Annu Rev Neurosci 2004, 27:509-547.

17. Sharma M, Burre J, Südhof TC: CSPalpha promotes SNARE-complex assembly by chaperoning SNAP-25 during synaptic activity. Nat Cell Biol 2011, 13:30-39.

18. Garcia-Reitböck P, Anichtchik O, Bellucci A, lovino M, Ballini C, Fineberg E, Ghetti B, Della Corte L, Spano P, Tofaris GK, Goedert M, Spillantini MG: SNARE protein redistribution and synaptic failure in a transgenic mouse model of Parkinson's disease. Brain 2010, 133:2032-2044.

19. Nakata Y, Yasuda T, Fukaya M, Yamamori S, Itakura M, Nihira T, Hayakawa H, Kawanami A, Kataoka M, Nagai M, Sakagami H, Takahashi M, Mizuno Y, Mochizuki H: Accumulation of alpha-synuclein triggered by presynaptic dysfunction. J Neurosci 2012, 32:17186-17196.

20. Kataoka M, Yamamori S, Suzuki E, Watanabe S, Sato T, Miyaoka H, Azuma S, Ikegami S, Kuwahara R, Suzuki-Migishima R, Nakahara Y, Nihonmatsu I, Inokuchi K, Katoh-Fukui Y, Yokoyama M, Takahashi M: A single amino acid mutation in SNAP-25 induces anxiety-related behavior in mouse. PLoS One 2011, 6:e25158.

21. Majewski $H$, lannazzo L: Protein kinase $C$ : a physiological mediator of enhanced transmitter output. Prog Neurobiol 1998, 55:463-475.

22. Morgan A, Burgoyne RD, Barclay JW, Craig TJ, Prescott GR, Ciufo LF, Evans GJ, Graham ME: Regulation of exocytosis by protein kinase C. Biochem Soc Trans 2005, 33:1341-1344.

23. Nagy G, Matti U, Nehring RB, Binz T, Rettig J, Neher E, Sorensen JB: Protein kinase $\mathrm{C}$-dependent phosphorylation of synaptosome-associated protein of $25 \mathrm{kDa}$ at Ser187 potentiates vesicle recruitment. J Neurosci 2002, 22:9278-9286.

24. Orimo S, Uchihara T, Nakamura A, Mori F, Kakita A, Wakabayashi K, Takahashi H: Axonal alpha-synuclein aggregates herald centripetal degeneration of cardiac sympathetic nerve in Parkinson's disease. Brain 2008, 131:642-650

25. Gureviciene I, Gurevicius K, Tanila H: Role of alpha-synuclein in synaptic glutamate release. Neurobiol Dis 2007, 28:83-89.

26. Bamford NS, Robinson S, Palmiter RD, Joyce JA, Moore C, Meshul CK: Dopamine modulates release from corticostriatal terminals. J Neurosci 2004, 24:9541-9552.

27. Wickens JR, Arbuthnott GW: Structural and functional interactions in the striatum at the receptor level. In Dopamine, vol. 21 of Handbook of Chemical Neuroanatomy. Edited by Dunnett SB, Bentivoglio M, Björklund A, Hökfelt T. Amsterdam: Elsevier; 2005:199-236.

28. Shimazaki Y, Nishiki T, Omori A, Sekiguchi M, Kamata Y, Kozaki S, Takahashi M: Phosphorylation of 25-kDa synaptosome-associated protein. Possible involvement in protein kinase C-mediated regulation of neurotransmitter release. J Biol Chem 1996, 271:14548-14553.

29. Iwasaki S, Kataoka M, Sekiguchi M, Shimazaki Y, Sato K, Takahashi M: Two distinct mechanisms underlie the stimulation of neurotransmitter release by phorbol esters in clonal rat pheochromocytoma PC12 cells. J Biochem 2000, 128:407-414

30. Shoji-Kasai Y, Itakura M, Kataoka M, Yamamori S, Takahashi M: Protein kinase C-mediated translocation of secretory vesicles to plasma membrane and enhancement of neurotransmitter release from PC12 cells. Eur J Neurosci 2002, 15:1390-1394.

31. Burgoyne RD, Morgan A: Chaperoning the SNAREs: a role in preventing neurodegeneration? Nat Cell Biol 2011, 13:8-9.

32. Hayes NVL, Baines AJ: Smallsynapticvesicles. In Biomembranes: a multivolume treatise. Edited by Lee AG. Greenwich, CT: JAl; 1996:75-122

33. Haucke V, Neher E, Sigrist SJ: Protein scaffolds in the coupling of synaptic exocytosis and endocytosis. Nat Rev Neurosci 2011, 12:127-138.

34. Li Y, Liu W, Oo TF, Wang L, Tang Y, Jackson-Lewis V, Zhou C, Geghman K, Bogdanov M, Przedborski S, Beal MF, Burke RE, Li C: Mutant LRRK2(R1441G) BAC transgenic mice recapitulate cardinal features of Parkinson's disease. Nat Neurosci 2009, 12(7):826-828.

35. Saito Y, Kawashima A, Ruberu NN, Fujiwara H, Koyama S, Sawabe M, Arai T, Nagura H, Yamanouchi H, Hasegawa M, Iwatsubo T, Murayama S: Accumulation of phosphorylated alpha-synuclein in aging human brain. I Neuropathol Exp Neurol 2003, 62:644-654.

36. Scott DA, Tabarean I, Tang Y, Cartier A, Masliah E, Roy S: A pathologic cascade leading to synaptic dysfunction in alpha-synuclein-induced neurodegeneration. J Neurosci 2010, 30:8083-8095.
37. Chung $C Y$, Koprich JB, Siddiqi $H$, Isacson O: Dynamic changes in presynaptic and axonal transport proteins combined with striatal neuroinflammation precede dopaminergic neuronal loss in a rat model of AAV alpha-synucleinopathy. J Neurosci 2009, 29:3365-3373.

38. Kuwahara T, Koyama A, Koyama S, Yoshina S, Ren CH, Kato T, Mitani S, Iwatsubo T: A systematic RNAi screen reveals involvement of endocytic pathway in neuronal dysfunction in alpha-synuclein transgenic $C$. elegans. Hum Mol Genet 2008, 17:2997-3009.

39. Morgan JR, Prasad K, Hao W, Augustine GJ, Lafer EM: A conserved clathrin assembly motif essential for synaptic vesicle endocytosis. J Neurosci 2000, 20:8667-8676

40. McFarland MA, Ellis CE, Markey SP, Nussbaum RL: Proteomics analysis identifies phosphorylation-dependent alpha-synuclein protein interactions. Mol Cell Proteomics 2008, 7:2123-2137.

41. Stoica G, Lungu G, Bjorklund NL, Taglialatela G, Zhang X, Chiu V, Hill HH, Schenk JO, Murray I: Potential role of a-synuclein in neurodegeneration: studies in a rat animal model. J Neurochem 2012, 122(4):812-822.

42. Tong J, Wong H, Guttman M, Ang LC, Forno LS, Shimadzu M, Rajput AH, Muenter MD, Kish SJ, Hornykiewicz O, Furukawa Y: Brain alpha-synuclein accumulation in multiple system atrophy, Parkinson's disease and progressive supranuclear palsy: a comparative investigation. Brain 2010, 133:172-188.

43. Yoshida M: Multiple system atrophy: a-synuclein and neuronal degeneration. Neuropathology 2007, 27:484-493.

44. Ubhi K, Low P, Masliah E: Multiple system atrophy: a clinical and neuropathological perspective. Trends Neurosci 2011, 34:581-590.

doi:10.1186/2047-9158-2-16

Cite this article as: Yasuda et al:: Neurodegenerative changes initiated by presynaptic dysfunction. Translational Neurodegeneration 2013 2:16.

\section{Submit your next manuscript to BioMed Central and take full advantage of:}

- Convenient online submission

- Thorough peer review

- No space constraints or color figure charges

- Immediate publication on acceptance

- Inclusion in PubMed, CAS, Scopus and Google Scholar

- Research which is freely available for redistribution 